\title{
Re: Wernicke's Encephalopathy After Laparoscopic Roux-en-Y Gastric Bypass: A Misdiagnosed Complication
}

\author{
Antonio Iannelli • Pietro Addeo • Jean Gugenheim
}

Published online: 10 June 2010

(C) Springer Science+Business Media, LLC 2010

Sir,

We thank Dr. Tageja for his insightful comments and acknowledge his contribution to this rare metabolic complication that may follow bariatric surgery [1].

Dr. Tageja $\mathrm{N}$ elucidates the correct pharmacologic half-life of thiamine that is a matter of minutes rather than days as previously shown by Serra et al. [2-4]. In fact, biologic half-life time of oral administered thiamine is $154 \mathrm{~min}$, whereas after i.v. administration, this is $96 \mathrm{~min}$ [5]. The time required to exhaust the total thiamine metabolic pool is approximately 20 days. In a healthy subject, any condition of unbalanced nutrition that lasts for 2-3 weeks may lead to thiamine depletion and Wernicke encephalopathy (WE) [2].

Normally, thiamine is absorbed in the entire duodenum and mostly in the acid milieu of the proximal duodenum [6]. However, despite that the duodenal absorption of

A. Iannelli $\cdot$ P. Addeo $\cdot$ J. Gugenheim

Pôle Digestif, Hôpital Archet 2,

Nice 06202, France

A. Iannelli $\cdot$ P. Addeo $\cdot$ J. Gugenheim

Université de Nice Sophia-Antipolis,

06107 Nice, France

A. Iannelli $\cdot$ J. Gugenheim

INSERM U895, Team 8 "Hepatic complications of obesity",

Université de Nice Sophia-Antipolis,

06204 Nice, France

P. Addeo $(\square)$

Division of General, Minimally Invasive and Robotic Surgery,

University of Illinois at Chicago,

840 S. Wood Street, Suite 435 E,

Chicago, IL 60612, USA

e-mail: pietroad@hotmail.com thiamine is rate-limited, as stressed by Dr. Tageja N, this is of no interest in the case of patients undergoing Roux-en-Y gastric bypass (RYGBP). In fact, in the anatomy of RYGBP, the ingested food and drugs do not pass through the duodenum that is "bypassed". Indeed, after RYGBP, most of the absorption is probably mediated through a saturable carrier-mediated exchange mechanism for thiamine transport across the human jejunum [7]. In WE after RYGBP, immediate parenteral administration of thiamine is needed instead of an oral administration. Oral administration is recommended after recovery and should be continued indefinitely at a dose of $50-100 \mathrm{~m}$ three times per day [8].

\section{References}

1. Iannelli A, Addeo P, Novellas S, Gugenheim J. Wernicke's Encephalopathy after laparoscopic Roux-en-Y gastric bypass: a misdiagnosed complication. Obes Surg; 2010. doi:10.1007/s11695010-0116-0.

2. Serra A, Sechi G, Singh S, et al. Wernicke encephalopathy after obesity surgery: a systematic review. Neurology. 2007;69(6):615. author reply 615-6.

3. Singh S, Kumar A. Wernicke encephalopathy after obesity surgery: a systematic review. Neurology. 2007;68(11):807-11.

4. Sechi G. Thyrotoxicosis-associated Wernicke's encephalopathy. J Gen Intern Med. 2008;23(6):897.

5. Tallaksen CM, Sande A, Bohmer T, et al. Kinetics of thiamin and thiamin phosphate esters in human blood, plasma and urine after $50 \mathrm{mg}$ intravenously or orally. Eur J Clin Pharmacol. 1993;44 (1):73-8.

6. Alvarez-Leite JI. Nutrient deficiencies secondary to bariatric surgery. Curr Opin Clin Nutr Metab Care. 2004;7(5):569-75.

7. Dudeja PK, Tyagi S, Gill R, et al. Evidence for a carrier-mediated mechanism for thiamine transport to human jejunal basolateral membrane vesicles. Dig Dis Sci. 2003;48(1):109-15.

8. Sechi G. Prognosis and therapy of Wernicke's encephalopathy after obesity surgery. Am J Gastroenterol. 2008;103 (12):3219. 